\title{
Análise da produção científica sobre comunicação terapêutica no campo da saúde, saúde mental e álcool e outras drogas
}

\author{
Analysis of scientific literature on therapeutic communication in health, mental \\ health and alcohol and other drugs
}

\author{
Marina Paranhos Jalles ${ }^{1}$, Viviane Silva Januário dos Santos ${ }^{1}$, \\ Amanda Márcia dos Santos Reinaldo²
}

\begin{abstract}
Jalles MP, Santos VSJ, Reinaldo MAS. Análise da produção científica sobre comunicação terapêutica no campo da saúde, saúde mental e álcool e outras drogas / Analysis of scientific literature on therapeutic communication in health, mental health and alcohol and other drugs. Rev Med (São Paulo). 2017 out.-dez:;96(4):232-40.
\end{abstract}

RESUMO: Introdução: A comunicação terapêutica é o conjunto de técnicas/habilidades/intervenções com potencial terapêutico no processo de recuperação e reabilitação no campo da saúde, com vistas a atender as necessidades do paciente. Objetivo: O objetivo deste trabalho é analisar as produções disponíveis sobre as técnicas, estratégias e importância da comunicação terapêutica em saúde, saúde mental e álcool e outras drogas. Metodologia: Trata-se de uma revisão narrativa da literatura de 2000 a 2016, cujos dados foram coletados de fevereiro a junho de 2016 na Biblioteca Virtual de Saúde (BVSBIREME) e Pubmed. Os descritores utilizados foram: dependência química, dependência de substâncias psicoativas e comunicação em saúde. Resultados: Foram encontradas 697 produções, sendo selecionados 15 artigos com texto completo disponível em suporte eletrônico e que obedeciam aos critérios de inclusão. Não foram encontradas publicações que abordassem a comunicação terapêutica no cuidado com os usuários de álcool e outras drogas. O maior número de publicações ocorreu entre os anos de 2004-2005, 2009 e 2012, com duas publicações em cada ano. Discussão: Os resultados apresentados evidenciaram a importância da comunicação terapêutica em saúde e no campo da saúde mental no processo de cuidar. Apesar de ser um instrumento de trabalho reconhecido, pouco tem se estudado no âmbito da saúde mental e álcool e outras drogas. Conclusão: A comunicação terapêutica é uma necessidade na construção e avaliação do Projeto Terapêutico Singular. Aponta-se a necessidade de estudos empíricos sobre o tema, associado ao cuidado com usuários de álcool e outras drogas.

Descritores: Comunicação em saúde; Usuários de drogas; Humanização da assistência; Saúde mental; Transtornos relacionados ao uso de substâncias/terapia.
ABSTRACT: Introduction: Therapeutic Communication is the set of techniques, abilities, and interventions used during health recovery and rehabilitation processes, in order to meet the patient's needs. Objective: The present work aims to review the existing literature about the techniques, strategies, and significance of Therapeutic Communication, not only in the general health field, but also in the mental health and alcohol/drugs field. Methodology: We undertook a Narrative Literature Review, from February until June 2016, collecting data and articles published between the years of 2000 and 2016, from Pubmed and Virtual Health Library (BVS-BIREME). The descriptors used were chemical dependency, psychoactive substances dependency, and communication in health environment. Results: In total, 697 papers were found; however, after a previous reading of the titles, abstracts and full texts, only 15 articles met the inclusion criteria for the present literature review. Papers that addressed the use of Therapeutic Communication in alcohol and drug addicts were not found during the research. Most of the selected scientific articles were published during the years of 2004, 2005, 2009, and 2012, with an average of two publications per year. Discussion: The results exposed the importance of Therapeutic Communication in the health care field and showed that, despite being a recognized health tool, little has been studied in the context of using the therapy in mental health and alcohol or drug addicted patients. Therapeutic Communication is an important tool that assists in the elaboration and evaluation of the Singular Therapeutic Project for the patients. Conclusion: We conclude that the field of Therapeutic Communication, while an important tool to understand the patient and create a personalized intervention, still needs further empiric research, especially when applied in alcohol and drug abuse contexts.

Keywords: Helath communication; Drug users; Humanization of assitance; Mental health; Substance-related disorders.

1. Faculdade de Ciências Médicas de Minas Gerais, Belo Horizonte, MG, BR. Acadêmica de Medicina. Email: mapjalles@hotmail.com, viane.1206@hotmail.com.

2. Escola de Enfermagem, Universidade Federal de Minas Gerais - UFMG, Belo Horizonte, MG, BR. Professora Associada; Doutora em Enfermagem Psiquiátrica. Email: amandamsreinaldo@gmail.com.

Endereço para correspondência: Marina Paranhos Jalles. Rua Montevideu, n. 212, bairro Parque Copacabana. Belo Horizonte - MG. CEP: 31550-140. mapjalles@hotmail.com. 


\section{INTRODUÇÃO}

Manual Diagnóstico e Estatístico de
Transtornos Mentais (DSM-5) diz que os transtornos relacionados a substâncias dividem-se em dois grupos: transtornos por uso de substância e transtornos induzidos por substância ${ }^{1}$.

São consideradas as seguintes classes de substâncias que definem o transtorno descrito no DSM 5: álcool; cafeína; Cannabis; alucinógenos (com categorias distintas para fenciclidina e outros alucinógenos); inalantes; opióides; sedativos, hipnóticos e ansiolíticos; estimulantes (substâncias tipo anfetamina, cocaína e outros estimulantes); tabaco; e outras substâncias (ou substâncias desconhecidas) ${ }^{1}$.

De acordo com o DSM 5, as condições a seguir podem ser classificadas como induzidas por substância: intoxicação, abstinência e outros transtornos mentais induzidos por substância/medicamento (transtornos psicóticos, transtorno bipolar e transtornos relacionados, transtornos depressivos, transtornos de ansiedade, transtorno obsessivo compulsivo e transtornos relacionados, transtornos do sono, disfunções sexuais, delirium e transtornos neurocognitivos) $)^{1}$.

A característica essencial de um transtorno por uso de substâncias consiste na presença de um agrupamento de sintomas cognitivos, comportamentais e fisiológicos indicando o uso contínuo pelo indivíduo, apesar de problemas significativos relacionados à substância. Outra característica importante é a alteração básica nos circuitos cerebrais que pode persistir após a desintoxicação, especialmente em indivíduos com transtornos graves. Os efeitos comportamentais dessas alterações cerebrais podem ser exibidos nas recaídas constantes e na fissura intensa por drogas quando os indivíduos são expostos a estímulos relacionados a elas. Uma abordagem de longo prazo pode ser vantajosa para o tratamento desses efeitos persistentes da droga ${ }^{1}$.

As intervenções propostas para os transtornos relacionados a substâncias visam, dentre outras, amenizar os sintomas provocados pela droga no organismo, a redução de danos e a identificação das consequências e dos condicionantes que levaram o sujeito ao uso e abuso da substância. A equipe multiprofissional envolvida no tratamento de usuários de álcool e outras drogas deve se ocupar não apenas com a doença, prescrição de medicamentos e aplicação de terapias, mas sim com o sujeito nas dimensões sociais, culturais, física, psíquica, espiritual e intelectual ${ }^{2,3}$.

A escuta e o diálogo em saúde possibilitam transformações e mudanças na forma como usuários dos serviços de saúde enfrentam o tratamento proposto e os aspectos de sua subjetividade. É nesse contexto que a comunicação terapêutica se apresenta como uma ferramenta fundamental para a condução do tratamento em saúde e a relação profissional paciente que se estabelece durante esse processo.

A comunicação é o meio pelo qual as pessoas interagem para troca de informações e compreensão do que se fala e ouve. As mensagens enviadas de uma pessoa a outra são capazes de exercer influência no comportamento e provocar mudanças no ambiente no qual a comunicação foi realizada ${ }^{4}$.

Existem três meios de transmissão de mensagens: o verbal, o não verbal e o para verbal. A comunicação verbal ocorre por meio da linguagem e dos signos e é por meio dela que atribuímos significado às coisas que não são ditas explicitamente, enriquecendo a compreensão da realidade. A comunicação não verbal são as mensagens enviadas por meio de gestos, postura, expressões faciais e corporais e pela distância mantida entre os indivíduos. Já a comunicação para verbal diz respeito ao tom de voz, ritmo, períodos de silêncio e entonação dada às palavras ${ }^{4}$.

Para que a comunicação seja efetiva, as mensagens enviadas pelo emissor precisam ser claras e organizadas de modo familiar ao receptor, que deve decodificá-la e respondê-la adequadamente. Os profissionais da área da saúde ora assumem papéis de emissores, ora de receptores, com a finalidade de investigação, informação, persuasão e entretenimento ${ }^{4}$.

A situação em que uma pessoa passa a contar, de certa forma, com a ajuda de profissionais da saúde para lidar com os seus problemas pode se constituir motivo de desconforto e insegurança. A comunicação com o paciente, nesse contexto, assume um papel de importância, pois é por meio dela que identificamos e compreendemos as necessidades apresentadas, além de fazer uma leitura sobre a percepção de mundo, que é importante para a adequação das mensagens que serão enviadas ${ }^{4,5}$.

Quando a comunicação é adequadamente empregada, há maior compreensão e reciprocidade entre as pessoas, aumentando a relação de confiança. No entanto, quando a comunicação de um profissional de saúde com um paciente não é bem empregada, podemos ter dificuldades na adesão do último, além de causar impactos negativos, como mal entendidos, que abalam a confiança e a segurança do paciente e/ou familiares para com a equipe de saúde como um todo.

A comunicação terapêutica é um tipo singular de comunicação dos profissionais de saúde. É utilizada para 
acolher, apoiar, informar, educar e capacitar às pessoas no processo de adaptação à situação de saúde vivenciada. Diz respeito ao diálogo efetuado pelo profissional de saúde que tem um potencial terapêutico no processo de recuperação, com vistas a atender às necessidades do paciente em todas as suas dimensões, considerando a sua cultura, o ambiente e o seu ser6.

A comunicação pode ser considerada terapêutica quando é benéfica à pessoa no sentido de lhe ajudar a lidar com os eventos da vida e ajustar ao que não pode ser mudado. Por outro lado, a comunicação pode ser não terapêutica ou até maléfica quando são utilizadas frases que podem denotar falta de empatia e desencadear sentimentos depressivos, ou quando não se escuta o que o outro tem a dizer, ou mesmo se uma linguagem inacessível prevalece, quando há julgamento do comportamento do outro ou é tirado dele o direito de tomar decisões em geral, o que demonstra a valorização de apenas um lado na relação ${ }^{7}$.

A comunicação terapêutica é importante em qualquer contexto de saúde, no entanto, em saúde mental assume extrema importância devido a natureza dos problemas e pelo impacto que tem ${ }^{2,8}$.

Diante do exposto, este estudo tem por objetivo analisar a produção disponível na literatura científica sobre as técnicas, as estratégias e a importância da comunicação terapêutica na abordagem em saúde, saúde mental e álcool e outras drogas.

\section{METODOLOGIA}

Trata-se de uma revisão narrativa da literatura. Os dados foram coletados no período de fevereiro a junho de 2016.

Os critérios de inclusão foram: artigos, teses ou dissertações, publicados em português, inglês ou espanhol a partir do ano de 2000, que apresentassem resumo na íntegra e cuja temática principal abordasse a comunicação terapêutica. A busca bibliográfica foi desenvolvida na Biblioteca Virtual de Saúde (BVS-BIREME) e na base de dados PUBMED. Os descritores utilizados foram: dependência química, dependência de substâncias psicoativas e comunicação em saúde.

Foi composta uma população de 697 produções. A partir da leitura prévia dos títulos e resumos foram selecionados 15 artigos com texto completo disponível em suporte eletrônico que obedeciam aos critérios de inclusão.

A análise dos estudos foi realizada, inicialmente, pela leitura dos títulos e resumos, seguida pela leitura integral dos artigos que se enquadraram nos critérios de seleção. Para o acesso ao texto completo foram usados os seguintes recursos: link disponível na base de dados, busca no portal do periódico em que o artigo foi publicado e buscador Google.

A análise de conteúdo foi realizada de acordo com o proposto por Bardin ${ }^{9}$ que consiste em três etapas: pré-análise, exploração do material e interpretação dos resultados. A leitura integral dos artigos selecionados possibilitou a identificação e transcrição dos resultados e de trechos de significância sobre o tema. Os artigos foram analisados e organizados pelas categorias: autor, ano de publicação, local de estudo, delineamento, amostra, assunto e abordagem, para facilitar na identificação.

As referências autorais foram identificadas para cada trecho e foi realizada uma análise dos textos, com fim de avaliar e sintetizar os pontos em comum, as divergências e semelhanças existentes entre os artigos. O processo analítico foi realizado em pares, de forma a garantir uma maior confiabilidade na estruturação e aprofundamento da análise.

\section{RESULTADOS E DISCUSSÃO}

Ao cruzar os descritores "comunicação em saúde", "dependência de substâncias psicoativas" e "dependência química", a amostra foi composta de uma população de 697 produções. Porém, a partir da leitura prévia dos títulos e resumos, não foi encontrado nenhum artigo, tese ou dissertação em que a temática principal "álcool e outras drogas" fosse identificada. Dessa forma, foram selecionados 15 artigos que abordavam a comunicação terapêutica na área da saúde, especificadamente, em saúde mental.

Dos quinze artigos selecionados, cinco eram artigos de revisão. Os demais trabalhos publicados abrangeram diferentes tipos e abordagens de estudos como: entrevistas semiestruturadas; questionários; grupo de discussões; diário de campo para registro de observações e roteiro de coleta junto a prontuários. O maior número de publicações foi encontrado nos anos de 2004-2005, 2009 e 2012, com duas publicações em cada ano. Em relação ao local do estudo, a maioria (33\%) foi realizada na região Nordeste do Brasil.

Os resultados apresentados evidenciaram a importância da comunicação terapêutica em saúde e no campo da saúde mental, especificamente para o processo de cuidar. Apesar de ser um instrumento de trabalho reconhecido, pouco tem se estudado no âmbito da saúde mental, álcool e outras drogas. 
Jalles MP, et al. Análise da PC sobre comunicação terapêutica no campo da saúde, saúde mental e álcool.

TABELA 1. Artigos incluídos na revisão de acordo com o autor, ano de publicação, local de estudo, delineamento, amostra, assunto e abordagem

\begin{tabular}{|c|c|c|c|c|c|c|}
\hline Autor & $\begin{array}{l}\text { Ano de } \\
\text { publicação }\end{array}$ & Local do estudo & $\begin{array}{l}\text { Delineamento de } \\
\text { estudo }\end{array}$ & Amostra & Assunto & $\begin{array}{l}\text { Abordagem da } \\
\text { temática }\end{array}$ \\
\hline $\begin{array}{l}\text { Benevides, } \\
\text { et al. }\end{array}$ & 2010 & $\begin{array}{l}\text { Serviço Substitutivo } \\
\text { Intermediário } \\
\text { (Hospital-Dia de um } \\
\text { Hospital Psiquiátrico) } \\
\text { em Fortaleza, CE) }\end{array}$ & $\begin{array}{l}\text { Pesquisa crítica } \\
\text { e reflexiva, com } \\
\text { abordagem qualitativa }\end{array}$ & $\begin{array}{l}14 \text { trabalhadores } \\
\text { de saúde mental } \\
\text { da instituição } \\
\text { pesquisada }\end{array}$ & $\begin{array}{l}\text { Abordagens terapêuticas } \\
\text { grupais no cuidado em } \\
\text { saúde mental }\end{array}$ & $\begin{array}{l}\text { Entrevistas } \\
\text { semiestruturadas e } \\
\text { observação }\end{array}$ \\
\hline Bertachini & 2012 & - & $\begin{array}{l}\text { Artigo de revisão, } \\
\text { delineamento não } \\
\text { descrito em detalhes }\end{array}$ & 17 publicações & $\begin{array}{l}\text { A comunicação } \\
\text { terapêutica como fator } \\
\text { de humanização da } \\
\text { Atenção Primária }\end{array}$ & $\begin{array}{l}\text { Análise de produções } \\
\text { disponíveis } \\
\text { na literatura e } \\
\text { legislações sobre a } \\
\text { temática }\end{array}$ \\
\hline Caron; Silva & 2002 & $\begin{array}{l}\text { Centro obstétrico de } \\
\text { dois hospitais da rede } \\
\text { SUS, do município de } \\
\text { São Paulo }\end{array}$ & $\begin{array}{l}\text { Estudo descritivo } \\
\text { e exploratório de } \\
\text { natureza qualitativa }\end{array}$ & $\begin{array}{l}15 \text { parturientes, } \\
02 \text { enfermeiras } \\
\text { obstétricas, e } 10 \\
\text { médicos }\end{array}$ & $\begin{array}{l}\text { A comunicação entre } \\
\text { os profissionais que } \\
\text { assistem o parto } \\
\text { de baixo risco e a } \\
\text { parturiente }\end{array}$ & $\begin{array}{l}\text { Entrevistas } \\
\text { semiestruturadas e } \\
\text { observação }\end{array}$ \\
\hline Dimenstein & 2004 & - & $\begin{array}{l}\text { Artigo de revisão } \\
\text { de cunho reflexivo, } \\
\text { analítico e qualitativo, } \\
\text { delineamento não } \\
\text { descrito em detalhes }\end{array}$ & 21 publicações & $\begin{array}{l}\text { A qualidade e } \\
\text { humanização das ações } \\
\text { de saúde mental }\end{array}$ & $\begin{array}{l}\text { Análise de produções } \\
\text { disponíveis na } \\
\text { literatura }\end{array}$ \\
\hline $\begin{array}{l}\text { Figueiredo, } \\
\text { et al. }\end{array}$ & 2013 & $\begin{array}{l}\text { Hospital público de } \\
\text { referência pediátrica } \\
\text { de Fortaleza (CE) }\end{array}$ & $\begin{array}{l}\text { Pesquisa descritiva, } \\
\text { com abordagem } \\
\text { qualitativa }\end{array}$ & $\begin{array}{l}14 \text { mães } \\
\text { acompanhantes }\end{array}$ & $\begin{array}{l}\text { O processo de } \\
\text { comunicação na } \\
\text { orientação acerca } \\
\text { do adoecimento e } \\
\text { da hospitalização da } \\
\text { criança por profissionais } \\
\text { de saúde para mães } \\
\text { acompanhantes. }\end{array}$ & $\begin{array}{l}\text { Entrevista } \\
\text { semiestruturada }\end{array}$ \\
\hline $\begin{array}{l}\text { Gomes, } \\
\text { et al. }\end{array}$ & 2012 & $\begin{array}{l}\text { Hospitais } \\
\text { psiquiátricos e um } \\
\text { serviço de psiquiatria } \\
\text { de um hospital geral } \\
\text { do distrito de Braga } \\
\text { (Portugal). }\end{array}$ & $\begin{array}{l}\text { Pesquisa exploratória- } \\
\text { descritiva }\end{array}$ & 07 enfermeiros & $\begin{array}{l}\text { A comunicação no } \\
\text { processo terapêutico } \\
\text { das famílias de doentes } \\
\text { mentais }\end{array}$ & $\begin{array}{l}\text { Entrevista } \\
\text { semiestruturada }\end{array}$ \\
\hline $\begin{array}{l}\text { Grigolo, } \\
\text { et al. }\end{array}$ & 2015 & $\begin{array}{l}\text { Equipes dos } \\
\text { Centros de Atenção } \\
\text { Psicossocial, de três } \\
\text { CAPS III, em um } \\
\text { município do nordeste } \\
\text { brasileiro }\end{array}$ & Pesquisa de campo & $\begin{array}{l}\text { Profissionais } \\
\text { (psicólogos, } \\
\text { psiquiatras, } \\
\text { enfermeiros, } \\
\text { assistentes } \\
\text { sociais, técnicos } \\
\text { de enfermagem, } \\
\text { terapeutas } \\
\text { ocupacionais) } \\
\text { das equipes dos } \\
\text { Centros de Atenção } \\
\text { Psicossocial. } \\
\text { Número amostral } \\
\text { não informado. }\end{array}$ & $\begin{array}{l}\text { A importância e as } \\
\text { características do Projeto } \\
\text { Terapêutico Singular } \\
\text { como um recurso } \\
\text { terapêutico no contexto } \\
\text { da clínica da atenção } \\
\text { psicossocial }\end{array}$ & $\begin{array}{l}\text { Grupos de Discussão } \\
\text { (GDs) }\end{array}$ \\
\hline
\end{tabular}


TABELA 1. Artigos incluídos na revisão de acordo com o autor, ano de publicação, local de estudo, delineamento, amostra, assunto e abordagem

continuação

\begin{tabular}{|c|c|c|c|c|c|c|}
\hline Autor & $\begin{array}{l}\text { Ano de } \\
\text { publicação }\end{array}$ & Local do estudo & $\begin{array}{l}\text { Delineamento de } \\
\text { estudo }\end{array}$ & Amostra & Assunto & $\begin{array}{l}\text { Abordagem da } \\
\text { temática }\end{array}$ \\
\hline $\begin{array}{l}\text { Kantorski, } \\
\text { et al. }\end{array}$ & 2005 & $\begin{array}{l}\text { Escolas públicas } \\
\text { de graduação em } \\
\text { Enfermagem do } \\
\text { Estado do São Paulo }\end{array}$ & $\begin{array}{l}\text { Pesquisa qualitativa e } \\
\text { descritivo-analítica }\end{array}$ & $\begin{array}{l}\text { Professores da área } \\
\text { de enfermagem } \\
\text { psiquiátrica e saúde } \\
\text { mental de } 8 \text { Escolas } \\
\text { de Graduação } \\
\text { em Enfermagem } \\
\text { públicas do Estado } \\
\text { do São Paulo }\end{array}$ & $\begin{array}{l}\text { A temática do } \\
\text { relacionamento } \\
\text { terapêutico e da } \\
\text { comunicação terapêutica } \\
\text { no ensino de graduação } \\
\text { em enfermagem }\end{array}$ & Questionário \\
\hline Oriá, et al. & 2004 & - & Artigo de reflexão & 21 produções & $\begin{array}{l}\text { As interfaces do } \\
\text { cuidado emocional ao } \\
\text { cliente hospitalizado. } \\
\text { Assistência em } \\
\text { enfermagem. }\end{array}$ & $\begin{array}{l}\text { Análise de produções } \\
\text { disponíveis na } \\
\text { literatura e reflexões } \\
\text { sobre a temática }\end{array}$ \\
\hline $\begin{array}{l}\text { Oliveira, } \\
\text { et al. }\end{array}$ & 2005 & $\begin{array}{l}\text { Centro de Terapia } \\
\text { Intensiva de uma } \\
\text { Instituição Pública de } \\
\text { João Pessoa (PB) }\end{array}$ & $\begin{array}{l}\text { Estudo qualitativo, } \\
\text { delineamento não } \\
\text { descrito em detalhes }\end{array}$ & $\begin{array}{l}08 \text { pacientes } \\
\text { internados }\end{array}$ & $\begin{array}{l}\text { Significado da } \\
\text { comunicação em } \\
\text { enfermagem }\end{array}$ & $\begin{array}{l}\text { Entrevista } \\
\text { semiestruturada }\end{array}$ \\
\hline $\begin{array}{l}\text { Pitia; } \\
\text { Furegato }\end{array}$ & 2009 & - & Artigo de reflexão & 32 produções & $\begin{array}{l}\text { O processo de } \\
\text { reabilitação psicossocial } \\
\text { e este tipo de ação } \\
\text { terapêutica na } \\
\text { saúde mental, com } \\
\text { base na clínica de } \\
\text { Acompanhamento } \\
\text { Terapêutico }\end{array}$ & $\begin{array}{l}\text { Análise de produções } \\
\text { disponíveis na } \\
\text { literatura e reflexões } \\
\text { sobre a temática }\end{array}$ \\
\hline $\begin{array}{l}\text { Pratta; } \\
\text { Santos }\end{array}$ & 2009 & - & Artigo de reflexão & 33 produções & $\begin{array}{l}\text { As bases teórico- } \\
\text { conceituais de três } \\
\text { eixos (saúde, doença e } \\
\text { dependência química) } \\
\text { e suas interseções. A } \\
\text { questão da promoção } \\
\text { da saúde frente à } \\
\text { dependência de drogas, } \\
\text { de acordo com o modelo } \\
\text { biopsicossocial presente } \\
\text { na atualidade. }\end{array}$ & $\begin{array}{l}\text { Análise de produções } \\
\text { disponíveis na } \\
\text { literatura e reflexões } \\
\text { sobre a temática }\end{array}$ \\
\hline $\begin{array}{l}\text { Pontes, } \\
\text { et al. }\end{array}$ & 2008 & $\begin{array}{l}\text { Hospital público, } \\
\text { situado na cidade } \\
\text { Fortaleza (CE) }\end{array}$ & $\begin{array}{l}\text { Pesquisa descritiva- } \\
\text { exploratória }\end{array}$ & $\begin{array}{l}12 \text { enfermeiras e } 14 \\
\text { pacientes }\end{array}$ & $\begin{array}{l}\text { O processo de } \\
\text { comunicação terapêutica } \\
\text { desenvolvida por } \\
\text { enfermeiros numa } \\
\text { unidade de internação } \\
\text { com base na teoria de } \\
\text { Peplau }\end{array}$ & $\begin{array}{l}\text { Entrevista semi- } \\
\text { estruturada, diário de } \\
\text { campo para registro } \\
\text { das observações e } \\
\text { um roteiro de coleta } \\
\text { junto ao prontuário }\end{array}$ \\
\hline Serqueira & 2014 & - & Editorial & - & $\begin{array}{l}\text { A importância, os } \\
\text { tipos e as técnicas de } \\
\text { comunicação terapêutica } \\
\text { em saúde mental }\end{array}$ & - \\
\hline Silva, et al. & 2000 & Não informado & Não informado & $\begin{array}{l}20 \text { alunas presentes } \\
\text { em um seminário } \\
\text { sobre Cinesia }\end{array}$ & $\begin{array}{l}\text { A importância da } \\
\text { linguagem corporal em } \\
\text { enfermagem }\end{array}$ & Questionário \\
\hline
\end{tabular}




\section{Breves considerações sobre a importância da humanização em saúde mental}

A saúde mental de uma pessoa pode ser considerada o fruto de um equilíbrio dinâmico e harmônico que resulta da interação com vários ambientes (internos e externos). É a capacidade de administrar a própria vida, descobrir aspirações e realizar algumas mudanças quando necessário, sendo também capaz de reconhecer também as limitações ${ }^{10}$.

Os esforços para humanizar os cuidados em saúde mental começaram com a Reforma Psiquiátrica Brasileira que, dentre outras coisas, visou a integralidade no atendimento aos pacientes, familiares e cuidadores, além da reintegração social dos primeiros. A humanização na saúde implica em alterações na gestão dos sistemas e seus serviços, sendo um processo que envolve mudanças de comportamento de cada profissional, com o objetivo de fornecer uma melhora na qualidade de atendimento aos pacientes, com foco no relacionamento interpessoal e numa atenção mais singular e ética ${ }^{11-14}$.

A humanização do cuidado exige que a relação entre a equipe de saúde, o paciente e os familiares seja de confiança, apoio, conforto, segurança, satisfação e capaz de gerar "vida" por meio do respeito e da ética profissional. Isso significa a possibilidade de tornar o ambiente terapêutico um local de menor sofrimento e ansiedade ${ }^{15}$.

O foco, nesse sentido, valoriza a comunicação e a escuta, sustentando-se a possibilidade de acolher diferentes formas de subjetivação, representadas pelas maneiras singulares de estar no mundo. Essa compreensão é importante levando-se em conta que o indivíduo portador de transtorno mental deve ser o protagonista no processo de superação de suas dificuldades ${ }^{2,7,15}$.

A humanização do cuidado depende da construção de uma relação de proximidade e afinidade com o paciente e da capacidade de comunicação do profissional, que deve levar em conta os recursos comunicativos do paciente, que descrevem sua história de vida e a sua percepção do mundo ${ }^{5}$.

A comunicação deve ser planejada para cada interação e adequada para cada paciente, lugar e contexto na qual ocorre. Caso contrário, seu sentido pode ser prejudicado. Em saúde, ela pode assumir as funções de investigação, informação, persuasão e entretenimento. O impacto de uma comunicação clara e adequada traz benefícios na aderência e no tratamento, bem como no entendimento entre a equipe multiprofissional ${ }^{4,5}$.

\section{Conceito, importância, competências e habilidades necessárias para que a comunicação terapêutica se estabeleça}

A comunicação terapêutica refere-se ao conjunto de técnicas/habilidades/intervenções comunicativas efetuadas pelos profissionais de saúde que de forma autônoma ou complementar tem um potencial "terapêutico" no processo de recuperação das pessoas, pois visa atender as necessidades do paciente em todas as suas dimensões ${ }^{5,7}$.

Dessa forma, a ideia da terapia através da comunicação é ajudar a pessoa em situação de tensão a diminuir a ansiedade, entender e participar do esquema terapêutico proposto, conviver melhor consigo e com outras pessoas, ajustar-se ao que não pode ser mudado e superar os bloqueios para enfrentar seus problemas. Além disso, facilita na compreensão da individualidade subjetiva do paciente, com suas crenças e valores, e na identificação dos problemas, permitindo melhor assistência ao paciente e a definição de suas necessidades ${ }^{4,5,6,16,17}$.

Certas competências desempenham papel central para que esses fins sejam alcançados, dentre elas: o bom relacionamento interpessoal, a capacidade de escuta, o acolhimento, a disponibilidade, a aceitação, a autenticidade, a sinceridade, a clareza, o respeito, a empatia, o interesse, o bom humor e a assertividade. A equipe de saúde deve comprometer-se também a oferecer respostas ao paciente, reforçando o princípio da reciprocidade na comunicação ${ }^{5,6,18}$.

Em relação a disponibilidade, envolve o estar disponível desde a recepção do usuário, como também nas conversas cotidianas e no acompanhamento e avaliação da participação nas atividades terapêuticas propostas. Uma ressalva, no entanto, é feita por Grigolo et al. ${ }^{20}$ ao afirmar que a disponibilidade não deve ser absoluta, posto que, em alguns momentos, não estar disponível para um usuário também pode ser terapêutico.

Segundo Bertachini ${ }^{5}$, são habilidades de comunicação que todo profissional de saúde deve ter: saber escutar, saber se comunicar de maneira clara, não mentir, evitar conspiração de silêncio e falsa alegria, não descartar uma possível esperança e aliviar a dor.

\section{Técnicas e estratégias de comunicação terapêutica}

A comunicação terapêutica deve ocorrer de forma natural e sensível às necessidades do sujeito, ancoradas em elementos técnicos e em marcadores temporais para condução do discurso, com a organização das ideias e disposição de tempo necessário para as expressões particulares ${ }^{5}$.

Existem algumas estratégias que podem ser implementadas na relação com o paciente, facilitando o processo terapêutico e o alcance dos objetivos da assistência. Essas estratégias são classificadas em três grupos: de expressão, de clarificação e de validação ${ }^{7,19}$.

As técnicas do grupo da expressão são muito importantes para encorajar os pacientes a expressar os seus pensamentos e sentimentos de ódio, medo, dor e ansiedade, bem como suas dúvidas e esperanças, estabelecendo o sentimento de confiança e demonstrando a disponibilidade e interesse em ajudar. Nesse grupo, encontram-se as 
seguintes técnicas: usar terapeuticamente o silêncio; ouvir reflexivamente; verbalizar aceitação; verbalizar interesse; usar frases incompletas; repetir as últimas palavras ditas pelo paciente; fazer pergunta; desenvolver a pergunta feita; usar frases descritivas; manter o paciente no mesmo assunto; permitir ao paciente que escolha o assunto; colocar em foco a ideia principal; verbalizar dúvidas; dizer não; estimular expressão de sentimentos subjacentes; e o uso terapêutico do humor ${ }^{4,7,19}$.

As técnicas do grupo de clarificação objetivam esclarecer o que for expresso pelo paciente e os possíveis não entendidos. Nesse grupo, encontram-se as seguintes técnicas: estimular comparações; solicitar que esclareça termos comuns; solicitar ao paciente que precise o agente de ação; e descrever os eventos em sequência lógica ${ }^{4,7}$.

As técnicas do grupo de validação auxiliam na ocorrência de significação comum do que é expresso. Nesse grupo, encontram-se as seguintes técnicas: repetir a mensagem do paciente; pedir ao paciente para repetir o que foi dito; ou sumarizar o conteúdo da interação $0^{4,7}$.

Segundo Serqueira ${ }^{6}$, as principais técnicas de comunicação terapêutica são: escuta, toque, posicionamento, olhar, informação, aceitação, silêncio, parafraseamento ou acentuação, questionamento/questões, explicitação/ clarificação, focalização, confrontação, assertividade, empatia, humor, validação, sumarização/síntese, anamnese associativa, reformulação, exploração, interpretação, orientação e feedback.

O toque, uma forma de comunicação não verbal, deve estar presente em toda assistência e não deve ser condicionado a realização de procedimentos técnicos, mas devem ter a finalidade de demonstrar carinho, empatia, segurança e proximidade em relação ao paciente. Todavia, é importante ficar atento aos sinais não verbais que a pessoa tocada manifesta, pois assim ela demonstra seu consentimento ou não em relação a essa invasão do seu espaço pessoal ${ }^{4,7}$.

Ouvir reflexivamente é uma das técnicas de comunicação terapêutica mais efetivas, pois é um dos principais meios através do qual obtemos informações importantes para o conhecimento e compreensão do sujeito que emite a mensagem. É também através da escuta que comunicamos nosso respeito, interesse e aceitação do paciente como ser humano, por isso, devemos nos atentar para controlar alguns dos nossos sentimentos e preconceitos para podermos compreender e aceitar o significado do que está sendo dito 4 .

A aceitação é uma das necessidades humanas básicas. A assistência às necessidades emocionais do paciente é tão importante como a assistência às necessidades físicas ${ }^{4}$.

As tensões passadas durante a internação podem comprometer a comunicação e o relacionamento entre profissional de saúde e paciente. Segundo Oliveira et al. ${ }^{4}$, demonstrar ou verbalizar aceitação permite ao paciente perceber o profissional como pessoa em quem pode confiar. Isso traz segurança e conforto, o que facilita o relacionamento terapêutico.

Aceitar o paciente não significa concordar com todas as suas manifestações, mas sim promover a mudança necessária para melhorar seu nível de saúde. A aceitação consiste da capacidade de uma pessoa compreender o ponto de vista da outra respeitando o direito de cada um em ser diferente, significando, assim, ausência de julgamento ${ }^{4}$.

Esse respeito e atenção também são demonstrados quando fazemos o uso terapêutico do silêncio. A postura mantida, as expressões faciais e as manifestações assumidas no momento em que se está próximo ao paciente em silêncio, podem transparecer impaciência. Ao empregar o silêncio, devemos estar atentos aos sentimentos do paciente como o medo, a ansiedade e a tristeza. A ideia dessa técnica é se colocar próximo ao paciente, demonstrando empatia e que ele não está sozinho ${ }^{4}$.

O uso da palavra para fazer perguntas apropriadas, claras e objetivas também são partes importantes no levantamento de dados. A pergunta deve ser usada com propriedade para obter informações específicas e estimular o paciente a dar continuidade ao assunto, esclarecendo suas ideias. Nesse caso, deve-se dar preferência às perguntas abertas. Uma ressalva feita por Oliveira et al. ${ }^{4}$ é em relação a não fazer várias perguntas ao mesmo tempo, pois pode resultar em fadiga por parte do paciente e o tornar receoso das intenções do profissional.

Ao devolver ao paciente a pergunta feita por ele, o profissional de saúde mostra que o ponto dele é o mais importante e ajuda o paciente a desenvolver um raciocínio sobre o assunto e a entender melhor a necessidade que gerou a pergunta. $\mathrm{Na}$ eminência de linguajares próprios do paciente de difícil compreensão, solicitar o esclarecimento de termos evita interpretações erradas ${ }^{4}$.

Estimular comparações também é uma técnica de terapia na comunicação e ajuda o paciente a descobrir semelhanças e diferenças entre as experiências vividas por ele. Segundo Oliveira et al. ${ }^{4}$, ao comparar situações, o paciente pode avaliar a influencia das pessoas e do ambiente nas suas experiências, renovar a confiança em suas forças e até mesmo compreender o porquê dos problemas que vivencia.

Outra técnica de comunicação terapêutica é a descrição das rotinas da unidade, dos procedimentos e das orientações. Essa comunicação deve ser simples, direta, adequada ao nível sociocultural do paciente e deve ocorrer quando houver demonstração de interesse por parte do paciente. A fala deve ser pausada, com tom adequado e vocábulo apropriado ${ }^{4}$.

O uso terapêutico do humor, desde que já se tenha 
estabelecido um relacionamento terapêutico com o paciente, também é uma ótima estratégia de comunicação, pois pode ajudar os pacientes e familiares a aliviar sentimentos como medo, ansiedade, raiva e depressão, fazendo com que esqueçam, por alguns momentos, do ambiente fechado e muitas vezes estressante da internação. Segundo Oliveira et al. ${ }^{4}$ até um comentário cômico sobre alguma imperfeição pode ser terapêutico, ajudando a resolver paradoxos e revelar novos pontos de vista para assuntos muitas vezes reprimidos.

\section{Barreiras de comunicação}

Segundo Caron e Silva ${ }^{7}$, embora a comunicação seja o meio para as pessoas compartilharem ideias, emoções e sentimentos, também pode ser recurso de opressão psicológica e moral. O Código de Ética Médica de 1847 já declarava que "a vida de uma pessoa doente pode ser diminuída não apenas pelos atos, mas também pelas palavras ou maneiras do médico" $"$.

Nesse sentido, os profissionais de saúde devem evitar usar a comunicação como exercício de relação de poder, com respostas incompletas, autoritárias, plena de duplas mensagens, impessoais, distantes e cheias de vocábulos impróprios para a compreensão. É necessário também vencer o desejo de dar respostas prontas sem antes escutar a mensagem ${ }^{5,7}$.

No processo de comunicação, certas barreiras podem surgir para dificultar ou mesmo impedir que ela ocorra eficientemente. Dentre elas, convém citar: falta de concentração, estereótipos e experiências anteriores, pressuposição de entendimento, ausência de significação comum, influência do inconsciente, falta de motivação, expectativas e emoções, presença de transtornos do humor, limitações do emissor/receptor, falta da habilidade para ouvir, sentir e compreender a mensagem do outro, limitação de tempo para o diálogo, excesso de ruídos, a comunicação confrontativa, distante e antipática e a comunicação antecipada. Acresce-se também o fato de os profissionais não se sentirem preparados, durante a formação acadêmica, para interagir com os pacientes ${ }^{4,5,7}$.

\section{REFERÊNCIAS}

1. Associação Americana de Psiquiatria. Manual diagnóstico e estatístico de transtorno: DSM-5. Porto Alegre: Artmed; 2014.

2. Pitia ACA, Furegato ARF. O acompanhamento terapêutico (AT): dispositivo de atenção psicossocial em saúde mental. Interface (Botucatu). 2009;30(13):67-77. doi: http://dx.doi. org/10.1590/S1414-32832009000300007.

3. Pratta EMM, Santos MA. O processo saúde-doença e a dependência química: interfaces e evolução. Psicol Teor Pesq (Brasília). 2009;25(2):203-11. doi: http://dx.doi.org/10.1590/ S0102-37722009000200008.

\section{CONCLUSÃO}

A comunicação não deve ser vista, em saúde, como um mero acessório de competência informativa. É fundamental que os profissionais tenham como essência a tríade sensibilidade, interesse e respeito com o paciente, e que sejam detentores de conhecimentos, habilidades e recursos que lhes permitam utilizar a comunicação como estratégia de ajuda ao outro, de forma a maximizar os ganhos em saúde.

Uma comunicação adequada, centrada na pessoa e no seu contexto, deve ser considerada como um dever ético e uma responsabilidade de qualquer profissional de saúde que trabalhe em contato direto com pessoas, de forma a garantir que os cuidados prestados para além da competência técnica, também tenham uma competência relacional e humana.

A escuta e o diálogo são ferramentas importantíssimas para quem lida com a saúde mental das pessoas, pois mesmo através de conversas corriqueiras sobre como o usuário se sente e como passou determinado dia, já se observam as possíveis transformações e mudanças na forma como ele está enfrentando o tratamento proposto, suas expectativas, suas necessidades e os aspectos de sua subjetividade.

É nesse contexto que a comunicação terapêutica entra como estratégia de cuidado na abordagem do usuário de álcool e outras drogas, uma vez que através dela abrese a possibilidade de participação do usuário no processo de reabilitação, na construção da sua autonomia e na corresponsabilidade no tratamento.

Tendo em vista que na presente revisão não foram encontrados nenhum material que abordasse a temática das estratégias, técnicas ou importância da comunicação terapêutica no cuidado com os usuários de álcool e outras drogas em processo de reabilitação, conclui-se que maiores contribuições literárias a respeito deveriam ser feitas.

É necessário um resgate, portanto, por parte dos profissionais de saúde, ao estudo da comunicação terapêutica no contexto das boas práticas em saúde mental, uma vez que se trata de um tema que pode contribuir na efetividade do projeto terapêutico singular, na educação dos profissionais de saúde e para a humanização do cuidado, sobretudo em saúde mental e dependência química.

4. Oliveira OS, Nóbrega MML, Silva ATMC, Ferreira-Filha MO. Comunicação terapêutica em enfermagem revelada nos depoimentos de pacientes internados em centro de terapia intensiva. Rev Eletrônica Enfermagem (Goiânia). 2005;7(1):54-63. doi: https://doi.org/10.5216/ree.v7i1.861.

5. Bertachini L. A comunicação terapêutica como fator de humanização da atenção primária. Mundo Saúde (São Paulo). 2012;36(3):507-20. Disponível em: http://www.saocamilo-sp. br/pdf/mundo_saude/95/14.pdf.

6. Serqueira C. Comunicação terapêutica em saúde mental 
[editorial]. Rev Portuguesa Enfermagem Saúde Mental (Porto). 2014;(12):6-8. Disponível em: http://www.scielo. mec.pt/pdf/rpesm/n12/n12a01.pdf.

7. Caron OAF, Silva IA. Parturiente e equipe obstétrica: a difícil arte da comunicação. Rev Latino-Am Enfermagem (Ribeirão Preto). 2002;10(4):485-92. doi: http://dx.doi.org/10.1590/ S0104-11692002000400004.

8. Gomes F, Amendoeira J, Martins M. A Comunicação no processo terapêutico de famílias de doentes mentais. Rev Portuguesa Enfermagem Saúde Mental (Porto). 2012;(7):5760. Disponível em: http://www.scielo.mec.pt/pdf/rpesm/n7/ n7a09.pdf.

9. Bardin L. Análise de conteúdo. Paris: Edições 70; 2008.

10. Fukuda IMK, Stefanelli MC, Arantes EC, organizadoras . Enfermagem psiquiátrica: em suas dimensões assistenciais. São Paulo: Manole; 2008.

11. Dimenstein M. A reorientação da atenção em saúde mental: sobre a qualidade e humanização da assistência. Psicol Ciên Profissão (Brasília). 2004;24(4):112-7. doi: http://dx.doi. org/10.1590/S1414-98932004000400013.

12. Benevides DS, Pinto AGA, Cavalcante CM, Jorge MSB. Cuidado em saúde mental por meio de grupos terapêuticos de um hospital-dia: perspectivas dos trabalhadores de saúde. Interface (Botucatu). 2010;14(32):127-38. http://dx.doi. org/10.1590/S1414-32832010000100011.

13. Brasil. Ministério da Saúde. Legislação em saúde mental: 1990-2004. 5a ed. Brasília (DF); 2004. Disponível em: http:// bvsms.saude.gov.br/bvs/publicacoes/legislacao_mental.pdf.

14. Brasil. Ministério da Saúde. Cadernos de atenção básica 34: saúde mental. Brasília (DF); 2013. Disponível em: http://189.28.128.100/dab/docs/portaldab/publicacoes/ caderno_34.pdf.

15. Figueiredo SV, Gomes ILV, Pennafort VPS, Monteiro ARM, Figueiredo JV. Comunicação terapêutica entre profissionais de saúde e mães acompanhantes durante a hospitalização do filho. Esc Anna Nery (Rio de Janeiro). 2013;17(4):690-97. doi: http://dx.doi.org/10.5935/1414-8145.20130013.

16. Pontes AC, Leitão IMTA, Ramos IC. Comunicação terapêutica em enfermagem: instrumento essencial do cuidado. Rev Bras Enferm (Brasília). 2008;61(3):312-8. doi: http://dx.doi. org/10.1590/S0034-71672008000300006.

17. Silva LM, Brasil VV, Guimarães HCQCP, Savonitti BHRA, Silva MJP. Comunicação não-verbal: reflexões acerca da linguagem corporal. Rev Latino-Am Enfermagem (Ribeirão Preto). 2000;8(4):52-8. doi: http://dx.doi.org/10.1590/S010411692000000400008 .

18. Kantorski LP, Pinho LB, Saeki T, Souza MCBM. Relacionamento terapêutico e ensino de enfermagem psiquiátrica e saúde mental: tendências no Estado de São Paulo. Rev Esc Enferm USP (São Paulo). 2005;39(3):317-24. doi: http://dx.doi.org/10.1590/S0080-62342005000300010.

19. Oriá MOB, Moraes LMP, Victor JF. A comunicação como instrumento para o cuidado emocional do cliente hospitalizado. Rev Eletrônica Enfermagem (Goiás). 2004;6(2):292-7. doi: 10.5216/ree.v6i2.808.

20. Grigolo TM, Peres GM, Garcia Junior CA, Rodrigues J. O projeto terapêutico singular na clínica da atenção psicossocial. Cad Bras Saúde Mental (Florianópolis). 2015;7(15):53-73. Disponível em: http://incubadora.periodicos.ufsc.br/index. $\mathrm{php} / \mathrm{cbsm} /$ article/view/2951/4437. 